\section{RHODODENDRON TOVERENE.*} Sp. n., F. von Mruell.

During a recent ascent of ranges fully 6,000 feet high in southeastern New Guinea, it fell to the fortunate lot of Mr. Carl Hunstein to discover a grand epiphyte, of which he brought a solitary flower, but made a colored sketch of the latter also (see Figure). Though it is unusual to define any plant botanically from a single flower, I feel no scruples in this exceptional case in placing at once this superb production of the Papuan flora on descriptive record, especially as the material, although scanty, allows of referring the plant clearly to the genus Rhododendron. Thus also I am enabled to fulfill a long-cherished wish to connect with some splendid floral treasure the name of the Marquis Goyzueta de Toverena, Consul-General in Australia for the Italian kingdom, a nobleman who has given much encouragement to my researches while worthily repre senting there for a series of years his great country.

Four species of Rhododendron are described from New Guinea in Dr. Beccari's Malesia, i., pp. 200, 202; they all came from Mount Arfak; so that the addition

of a southeastern species renders it probable that these superb plants occur in numerous specific forms through ot $t$ the higher regions of the Papuan island. This fifth congener differs in its white and very large flowers tographed and placed in the rims of his spectacles; from the other four; but R. Konori has also a 7 lobed lawyer, his briefs; a clergyman, his sermons; a bicycorolla (a characteristic

otherwise only recorded in

R. Fortunei), and the number of stamens is also about the same as in R. Toverenæ, while the anthers are likewise remarkablyelongated. Among the Sikkim species of Rhododendron our new one approaches to $R$. Ed worthi; but the flowersare numerous (forming indeed, according to the collector's note, magnificent umbellike bunches of over a foot's width), the limb of the corolla is broader, the tube much longer, the stamens become increased in proportion to the corolla lobes, and the anthers are longer and pale colored, while (as noted by the finder of the plant) the stigma and upper part of the style are deep red; the foliage may also prove very differ-

Our plant comes nearer to R. Falconeri, so far as the copious masses of its flowers, the much-lobed corolla, and the numerous stamens are concerned but the length and width of the flowers is much greater, and the shape of the corolla is not campanulate. Indeed, only R. Griffithi in its variety Aucklandi comes up to the size landi comes up to the size renæ; the latter, however, is distinguishe by the is distinguishe by the

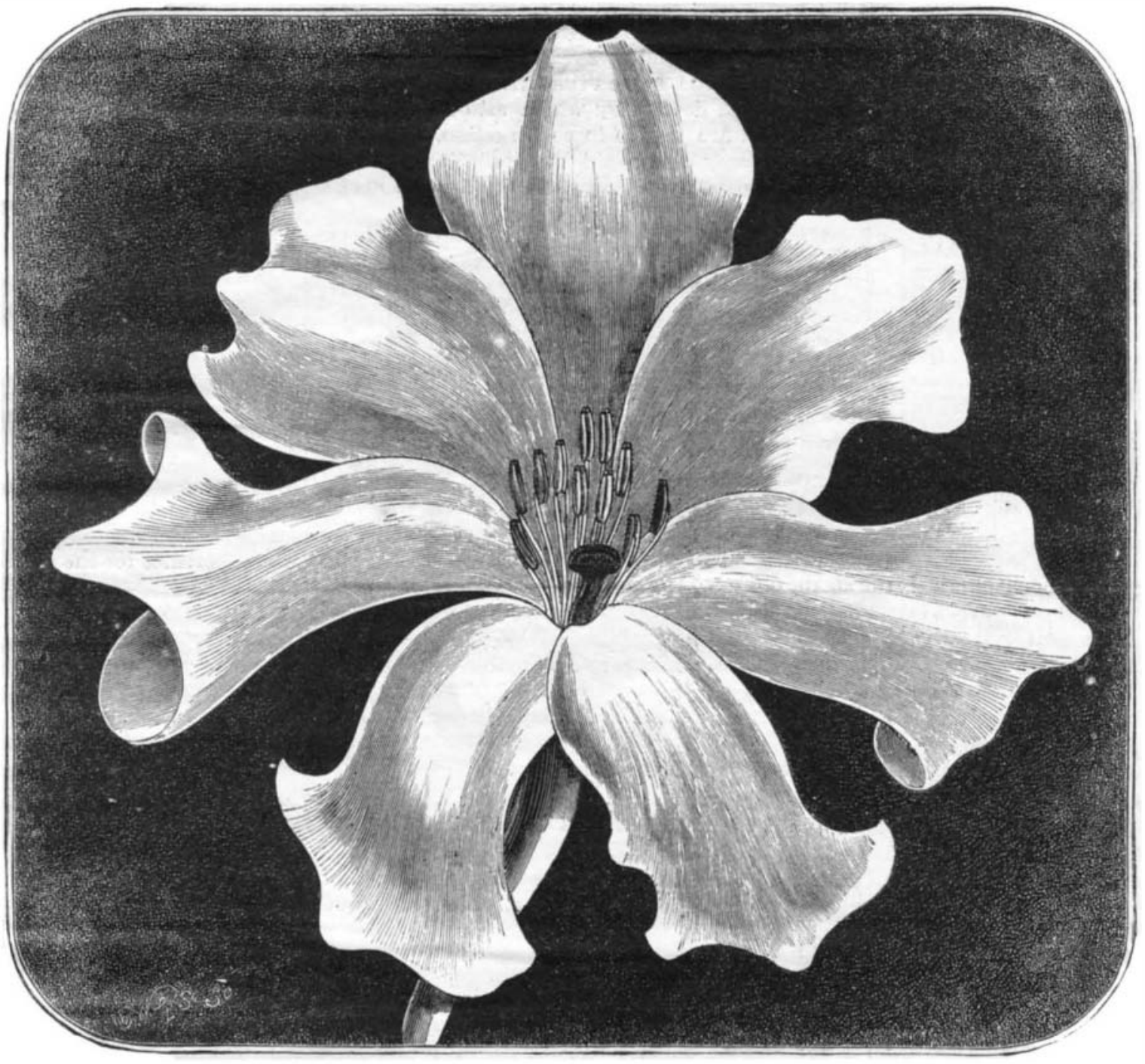

NEW RHODODENDRON FROM NEW GUINEA.-FLOWERS WHITE.
The Uses of Old Bones.

The minute photographs are placed behind suitable minute magnifying glasses, and are so arranged in or eyes of the wearer may see either one or all of the photographs without moving the spectacles.

The rim in or along which the minute photograph selves or a detachable rim, which may be applied to ny spectacles, eyeglasses, or eyeglass. scapes, or any object or group of objects from which a

For a student.-The series of microphotographs in the spectacles might consist of copies of an was studying would be constantly before his eyes io eference in his spare moments with containing the microphotographs bein mor contain considerable neatsfoot oil; about a pint from every four feet of skin and thigh bones are thoroughly cleansed of all meat and grease. The liboiled was formerly thrown away, but now a very fair quality of sizing glue is manufactured from it. for boneblack or converted into fertilizers, but the bulk of them are worked up into knife handles.

The round shin bone comes from the hind leg, and the flat from the fore leg. The bulk of the shin bones in the Eastern market are shipped to Europe, though there is a manufac. tory at Newburyport, $\mathrm{Mass}$. The knuckles of the shin bones are sawed off, and used either for lampblack or fertilizers. Shin bones over $\$ 40$ per ton, but for burning, etc., only about $\$ 25$ perton. The knuckles of thigh bones are also sawed off and used for boneblack or fertilizers. The thigh bones are worth $\$ 80$ per ton, and are manufactured into tooth brush handles. Very few are exported.

The front leg bones of cattle are worth about $\$ 30$ per ton, and manufactured into collar buttons, fancy bone trimmings, jewelry, parasol handles, etc., both here and in England. The American factories are in
The minute photographs may be photographs of photograph may be taken.

be applied are the following: ject the student wished to study. Thus, the subject he rrying books about with him.

\section{The leg bones of cattle and
The} quor in which they were for knife handles will bring

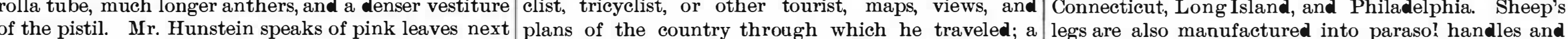
the flowers, which would accord with youngleaf-shoots shopkeeper, a calendar, ready-reckoner, etc.; a timber various fancy articles. The bone waste and dust causof red tinge, such as are observed in several Rhododen- merchant or builder, cubes, measurements, and rules; of red tinge, such as are observed in several Rhododen- merchant or builder, cubes, measurements, and rules; \begin{tabular}{l|l} 
drons, particularly R. Fortunei and R. Hookeri. A travelers on the Continent, list of foreign terms, names \\
consideration of the fact that the calyx in many species & of articles, foreign money, tables, and so on; a corre-
\end{tabular} of Rhododendron becomes obliterated strengthens the $\mid$ spondent, an abridged dictionary of technical or diffiview that the floral envelope of Proteacere and a few cult words; a member of Parliament, facts and figures orders allied to them is petaline, not calycine.-Ferd. von Mueller, The Gardener's' Chronicle.

$$
\text { The Microphotoseope. }
$$

Mr. R. G. Mason, of Douglas, Isle of Man, is the author of the following:

The microphotoscope consists of a pair of spectacles, eyeglasses, or an eyeglass, with one or a number of minute photographs arranged in or along the rim of the spectacles, eyeglasses, or eyeglass.

* Rhododendron Toverence.-Corymbs containing about twelve flowers, each on an average 6 inches long and wide; calyx reduced to a terminal narrow oblique expansion of the stalklet, the latter nearly glabrou corolla pure white, its tube slender cylindrical, about 3 inches long, but
not half an inch wide at the middle, slightly widened upward, lobes siona ly sinuous at the rounded-blunt or according to the sketch) occalobules; stamens fourteen, somewhat exserted, about 4 inches long, filaments in their lower portion densely beset with short spreading hair, in the upper portion nearly glabrous; anthers linear-cylindrical, nearly or
fully half an inch long; pistil hardly longer than the corolla tube, fully half an inch long; pistil hardly longer than the corolla tube,
cover of the stigma patellar, ovary 7 celled, stigma 7 lobed, style abont cover of the stigma patellar, ovary 7 celled, stigma 7 lobed, style abont
136 Inches long, as well as the ovary fulvous-velvety, except toward the summiti. $-F . v . M$. relating to the subject of his speech; a doctor, formulæ;
a public entertainer, recitations, songs, bon-mots, etc.; nals wanted.

The inventor says: "It will also be evident that the microphotoscope may be applied to a variety of other uses too numerous to mention.

It will be understood that the spectacle or eyeglass frames may have in them ordinary reading-glasses when worn by those who need them, and when worn by those who do not, they may have either plain glasses or no glasses at all.

Influence of Petroleum Cans on the Compass.

It is now claimed that refined petroleum in tin cases exerts an influence on the compasses of a vessel equal to the same amount of iron or steel. The masters of the German ship J. Weisselholm and the schooner Iaggie Dalling have made written reports confirming the above, and in the latter case the captain claims that his vessel we a musician. whole pieces of music; a detective, crimied by the sawing, etc., is used as a feed for cattle and hens, and is also worke up into boneblack and fertilizers.

Boston, according to the Commercial Bulletin of that city, is a smaller bone market than formerly, as the gradual falling off in the slaughter of cattle in that vicinity, and the increase in the West, has caused a decrease in the amount of bones coming into that market. ceived at that port, and are either bougl. ' oy boneblack or fertilizer manufacturers or shipped to England.

\section{coal in wyoming}

In cutting the 1,400 foot tunnel of the Oregon Short Line at Twin Creek, Wyoming, seven veins of coal were pierced. These dip at an angle of about 40 degrees, and are 5, 7, 8, and 20 feet thick. On the west side of veins, respectively 5,8 , and 10 feet, and is tunneling for another vein 18 feet thick. At Mine No. 2 they are extracting from a 14,foot vein. This coal burns to a white ash, is a good steaming coal, but possesses the defect of slaking badly upon exposure to the air. In mining, about one-fourth is waste, because of this disposition to slake and crumble. It was so big the purchasers made money.
A Virginia walnut tree was recently sold for $\$ 600$ 
Surface Life in the Gulf Stream.

The explorations of the U. S. Fish Commission, chiefly within the last two years, have brought to light many wonderful facts connected with the Gulf Stream. The deep water dredgings of 1883 , and now more strikingly of 1884 , have added multitudes of new types of
both vertebrates and invertebrates, illustrating those both vertebrates and invertebrates, illustrating those features of the deep sea fauna which have been becom-
ing so conspicuous and characteristic in the zoological reports of the last year and more. It is not with the individual forms that we have now to deal, but merely with the fact that in those immense depths, 2,000 fathoms and beyond, the bottom of the sea swarms with animal life to a degree that appears almost in credible. The actual bed itself is alive with crust ceans, mollusks, radiates, etc., while the stratum of water so near to it as to be within the depth of a trawl's mouth is filled with fishes prowling about for food. Whether the mass of water between these strata of the bottom and those of the surface is full of living objects, we have as yet no means of knowing.

The trawls pass through all in their descent and their ascent, and part of what they eventually contain
may perhaps have been captured in mid-depth, but it is not probable that this can take place to any considerable extent.

At all events, our real explorations have to do chiefly th with the surface and the bottom; and the results obtained at the surface are in some respects more wonderful than those from the deep dredgings. The working of the trawls has been freely described and figured but little has been said of the collections made within a depth of less than two feet, and yet zoologically they are rich beyond all description, and biologically they set before us a problem which is not easy of solution. The means of collecting are exceedingly simple. nets, being in either case a metallic ring to which a deep gauze bag is attached. They can be used to advantage only while the vessel is in very gentle motion; and the first impression made by the use of a drag net in the Gulf Stream for even a very short time is of simple, unbounded astonishment at the apparently limitless prof usion of animal life. One is tempted to believe that the vessel is floating, not on water which contains animals, but on a sea of minute living objects with barely suffcient water to give them freedom of motion. The gauze bag speedily becomes so completely clogged with its living load that no water can pass through it until it is cleared. Drawing it in and empty ing it into a bucket, perhaps a gallon of "pudgreater number of distinct and independent living beings than there are human inhabitants of the earth at this moment

This is no exaggeration. The numbers are utterly beyond computation. Of course all of these are of extreme minuteness, for the larger species easily escape the slow moving net. The smaller crustacea (oopepods, branchiopods, etc.) the swimming mollusks (pteropods mostly, though not a few cephalopods are among them) various forms of annelids, the tunicates (most especially the salpæ)-these are swept into the net through whose interstices in the mean time the more minute objects have been escaping; but as the more minute objects have been escaping; but as the the little things which are really microscopic are de tained on its surface, and serve to increase the mass, though hundreds of thousands and even millions are needed before they become fairly appreciable. The larval stage of the echinoderms is represented with an almost infinite richness, and with them come the hydroids and jelly fishes, and then the infusoria, the droids and jelly fishes, and then the infusoria, the
foraminifera, till we reach absolutely the lowest grades of animal life, including the well known globigerinæ, whose microscopic silicious shells are constantly helping to build up the soft ooze at the greatest ocean depths. These are the objects which the gauze net has collected while dragged slowly along for perhaps one to two hundred yards. And if we have gathered our hundreds of millions of individuals within such an extent, what effort of the imagination can stretch out to tent, what effort of the imagination can stretch out to
numbers which shall even approximately reckon up the surface life in the Gulf Stream, were we to take but even a single square mile of its extent? For it is worthy of note that this richness is not the result of concentration.

In other places (we have a notable example at Wood's Holl) there are certain occasions when, for a brief period owing to the run of the tide, and the eddies caused thereby, we may find a state of swarming animal life as remarkable as that which we have specified, but it is only for a very restricted space; whereas in the Gulf Stream, so evenly diffused are the teeming myriads,
that out of 150 sweeps of the net only one or two will fail to realize very nearly what we have stated.

Nor is it only in numbers of individuals that the lavish profusion exists; the catalogue of distinct types, reckoned as species, is certainly full of suggestiveness Without counting the majestic and powerful animals,

dant supply of food-the whales, blackfish, porpoises, / space that to an ordinary observer they are invisible. etc., and with them the fierce sharks in swarms, together The speed may be varied from three miles to ten miles with the fleet and savage dolphins, albicore, bassacu- per hour.

das, and so on-it is safe to count the smaller fishes up Electric tram cars propelled by accumulators have to 25 at the very least. Of the crustacea in their vari- been made and tried on several occasions in London, ous grades, there are certainly 50 species. The mollusca Paris, and Brussels, but hitherto with little success, and have 60 distinct specific forms, probably more. Of the eminent men have pronounced the accumulator sysannelids we find 15; of the tunicates, 8; of the poly- tem of motive power as impracticable. One of the drozoa, certainly as many as 25; while the radiolaria, too heavy. The Electrical Power Storage Company foraminifera, and other infusoria reckon up 30 as a has, we are told, reduced the weight without sacrificminimum. These give us 228 species, which total will ing either efficiency or durability. The accumulators surely be enlarged by further research.
in the car under notice weigh $1 \frac{11 / 4}{1}$ tons, the motor,

\section{MACHINE FOR FRAMING TIMBER.}

The engraving shows a machine for cutting tenons upporting the earth and rock around shaft drift, for unnel cuttings, and for use in framing timbers for other purposes. The two saws are mounted upon fixed frame so as to rotate at right angles to each other, and so as to cut to the same line both ways ward and backward motion, and is provided with rotatable timber clamps, by which the timber may be turned axially, in order to present all of its faces to the saws. That portion of the carriage which carries thus permitting both ends of the timber to be presented to the saws. The timber clamp frame is adjustable toward and away from the saws, to gover the length of the framed timbers.

The various devices by which all of these motions are effected are simple in construction, durable, and placed as to be within convenient reach of the operat-

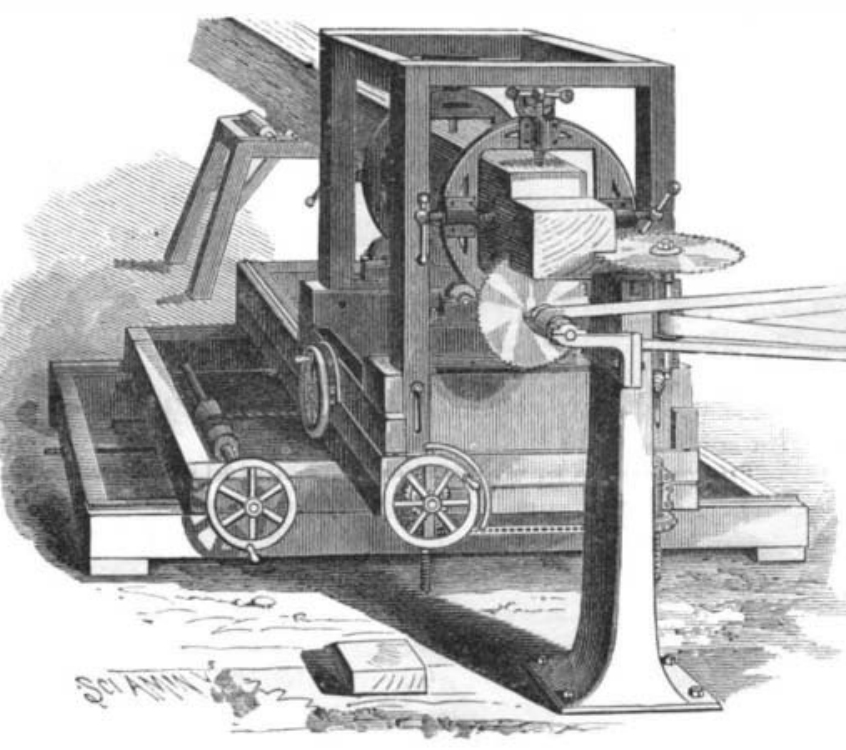

BLEX'S MACHINE FOR FRAMING TIMBER.

or. It will also be seen that when once placed in the operator.

Additional information concerning this timber framng machine can be obtained by addressing the inventor, Mr. William J. Bley, of Silver King, Arizona.

\section{An Electric Tram Car.}

Experiments have been carried out for a few months past in a quiet and systematic way with a view of determining the value of secondary batteries, in conjunction with electro motors, for the propulsion of tram cars in crowded cities. Mr. A. Reckenzaun has designed, and the Electrical Power Storage Company has constructed, apparatus which, says the Engineer, promises a very handy means of locomotion on street rails, and for more than two months past a car has been running on a line put down for experimental purposes in the
yard of the Storage Company at Millwall. The line4 feet $8 \frac{1}{2}$ inches gauge-is 400 feet long, forming a right angle of nearly equal sides, so that about half way a curve of 35 feet radius has to be passed. From one end, as far as the commencement of the curve, the road is tolerably level; but with this curve commences an in-
cline of 1 in 40 , which rises gradually until it reaches the maximum of 1 in 17 nearly at the end of the up journey; thus it is impossible to make a rush for the hill, on account of the sharp curve intervening. The car itself is an old one procured from one of the metropolitan tramways, and it has done many years
service while drawn by horses on the Greenwich, Westminster line. The body of this vehicle weighs $21 / 2$ tons, and it accommodates forty-six passengers. The
accumulators furnishing the electric energy are of a accumulators furnishing the electric energy are of a special type manufactured by the Storage Company,
to the designs of Mr. Reckenzaun. Stowed under the seat on long trays, which run on rollers for their speedy removal, they are out of sight, and the whole car internally and externally has the ordinary appearance. The motor and gearing-Reckenzan's patent-
are placed underneath the car, and occupy so little in the car under notice weigh $1 \frac{1}{4}$ tons, the motor,
gearing, and accessories weigh about $1 / 2$ ton, bringing the total weight of motive power to $1 / 4$ tons for a car which, with its full complement of passengers, weighs itself $51 / 2$ tons; while the batteries, motor, and gearing re capable of furnishing at any desired moment a weight of 1144 tons, with that of a steam tramway locomotive, or a compressed air locomotive, either of which will weigh some eight or ten tons to do the same amount of useful work, stored electricity has the ad-
vantage in proportion of about five to one, so long as the propelling force is directly proportional to the weight moved. It has also been said that there is a reat waste of power in the use of accumulators for hrough several stages, viz., steam into electric current, current into oxygen and hydrogen, and these again into current and electro-motive power. It can be shown rom prolonged experiments and practice that the total oss of energy with all these transformations is 66 per cent between the steam engine and the tram rails. Tramway steam locomotives consume from three to times as much fuel per horse power as large sta-
tionary engines, such as would be used for driving. dynamo machines; and bearing this in mind, an efficiency in the electrical tram car far below the one quoted above would still be considered economical. The prime cost of the electrically propelled cars. with the charging station is less than steam cars, and the depreciation and repairs of machinery must also be less, on account of the few wearing parts and the complete protection from dirt.

The running cost, including 15 per cent depreciation on machinery and 50 per cent on accumulators, is given as $3.5 \mathrm{~d}$. per car mile, which is about one-half of the cost of horsing on tram lines. The car on the line at Millwall runs for two hours with one charge, starting, stopping, and reversting every sixty seconds, and the discharged accumlilators can be replaced, it is said, almost as quickly as changing a pair of horses, by means of a trolly, which brings and removes the trays of cells, running on rollers. The whole arrangement has been very carefully worked out in every detail, the mechanical parts being as well arranged. The load is distributed upon two small bogies, so that no objection can be raised on the part of tramway companies using light rails laid for horse car traffic,
and the old rolling stock can be readily utilized by putting the bogies which carry the motor under reception of the accumulators. The car is brilliantly lighted by four 20 candle power. Swan lamps, and bell pushes inside the vehicle enable the passengers to call the conductor and driver at the same time by the ringing of electric bells.

\section{Rise of the Swedish Coast.}

An examination of a series of water marks set in 1750 all round the Swedish coasts, from the mouth of the Tornea to the Naze, in order to settle a dispute between the Swedish astronomer Celsius and some Germans, as to whether the level of the Baltic had been rising or sinking, shows that both parties were right. The gauges were renewed in 1851, and again this year, and have been inspected regularly at short intervals, the observations being carefully recorded. It appears, says Nature, that the Swedish coast has been steadily risbeen as steadily falling. The dividing line, along which no change is perceptible, passes from Sweden to the Schleswig-Holstein coast, over Bornholm and Laland. The results have lately been published by the Swedish Academy of Sciences; and it appears from them that while during this period of 134 years the northern part of Sweden has risen about 7 feet, the rate of elevation gradually declines as we go southward, being only which remains at the same level as in the middle of the last century. The general average result would be that the Swedish coast had risen about 56 inches during the last 134 years.

THE friends of Professor Huxley will be pained to learn that his health is so impaired that he is obliged vicesend the winter in southern Europe. From lastadaples, and is already much the better for rest and change. He will pass a month or two at the interesting old city of Am
hoped he will regain perfect health. 